\title{
Operation of a Four-cylinder 1.9L Propane Fueled Homogeneous Charge Compression Ignition Engine: Basic Operating Characteristics and Cylinder-to Cylinder Effects
}

D. Flowers, S. Aceves, J. Martinez-Frias, R. Smith M. Au, J. Girard, R. Dibble

This article was submitted to

Society of Automotive Engineers "Spring" Fuels and Lubricants Conference and Exposition, May 7-9, 2001, Orlando, Florida

Lawrence

Livermore

National

Laboratory

March 12, 2001 


\section{DISCLAIMER}

This document was prepared as an account of work sponsored by an agency of the United States Government. Neither the United States Government nor the University of California nor any of their employees, makes any warranty, express or implied, or assumes any legal liability or responsibility for the accuracy, completeness, or usefulness of any information, apparatus, product, or process disclosed, or represents that its use would not infringe privately owned rights. Reference herein to any specific commercial product, process, or service by trade name, trademark, manufacturer, or otherwise, does not necessarily constitute or imply its endorsement, recommendation, or favoring by the United States Government or the University of California. The views and opinions of authors expressed herein do not necessarily state or reflect those of the United States Government or the University of California, and shall not be used for advertising or product endorsement purposes.

This is a preprint of a paper intended for publication in a journal or proceedings. Since changes may be made before publication, this preprint is made available with the understanding that it will not be cited or reproduced without the permission of the author.

This report has been reproduced directly from the best available copy.

Available electronically at http://www.doc.gov/bridge

Available for a processing fee to U.S. Department of Energy

And its contractors in paper from

U.S. Department of Energy

Office of Scientific and Technical Information

P.O. Box 62

Oak Ridge, TN 37831-0062

Telephone: (865) 576-8401

Facsimile: (865) 576-5728

E-mail: reports@adonis.osti.gov

Available for the sale to the public from

U.S. Department of Commerce

National Technical Information Service

5285 Port Royal Road

Springfield, VA 22161

Telephone: (800) 553-6847

Facsimile: (703) 605-6900

E-mail: orders@ntis.fedworld.gov

Online ordering: http:/ / www.ntis.gov/ordering.htm

\section{OR}

Lawrence Livermore National Laboratory

Technical Information Department's Digital Library

http: / / www.llnl.gov/tid/Library.html 


\title{
Operation of a Four-Cylinder 1.9L Propane Fueled Homogeneous Charge Compression Ignition Engine: Basic Operating Characteristics and Cylinder-to-Cylinder Effects
}

\author{
Daniel Flowers, Salvador M. Aceves, Joel Martinez-Frias, J. Ray Smith \\ Lawrence Livermore National Laboratory \\ Michael Au, James Girard, Robert Dibble \\ University of California Berkeley
}

\begin{abstract}
A four-cylinder 1.9 Volkswagen TDI Engine has been converted to run in Homogeneous Charge Compression Ignition $(\mathrm{HCCl})$ mode. The stock configuration is a turbocharged direct injection Diesel engine. The combustion chamber has been modified by discarding the in-cylinder Diesel fuel injectors and replacing them with blank inserts (which contain pressure transducers). The stock pistons contain a reentrant bowl and have been retained for the tests reported here. The intake and exhaust manifolds have also been retained, but the turbocharger has been removed. A heater has been installed upstream of the intake manifold and fuel is added just downstream of this heater.
\end{abstract}

The performance of this engine in naturally aspirated $\mathrm{HCCl}$ operation, subject to variable intake temperature and fuel flow rate, has been studied. The engine has been run with propane fuel at a constant speed of 1800 $\mathrm{rpm}$. This work is intended to characterize the $\mathrm{HCCl}$ operation of the engine in this configuration that has been minimally modified from the base Diesel engine. The performance (BMEP, IMEP, efficiency, etc) and emissions $\left(\mathrm{THC}, \mathrm{CO}, \mathrm{NO}_{\mathrm{x}}\right)$ of the engine are presented, as are combustion process results based on heat release analysis of the pressure traces from each cylinder.

\section{INTRODUCTION}

Homogeneous Charge Compression Ignition ( $\mathrm{HCCl})$ engines are being considered as a future alternative for diesel engines. $\mathrm{HCCl}$ engines have the potential for high efficiency (diesel-like;[1]), very low oxides of nitrogen $\left(\mathrm{NO}_{\mathrm{x}}\right)$ and very low particulate emissions, and possibly lower cost (because no high-pressure injection system is required). Disadvantages of $\mathrm{HCCl}$ engines are: high hydrocarbon $(\mathrm{HC})$ and carbon monoxide (CO) emissions, high peak pressures, high rates of heat release, lower power density, difficulty in starting the engine, and difficulty of control.

$\mathrm{HCCl}$ was identified as a distinct combustion phenomenon about 20 years ago. Initial papers recognized the basic characteristics of $\mathrm{HCCl}$ that have been validated many times since then: $\mathrm{HCCl}$ ignition occurs at many points simultaneously, with no flame propagation [2, 3]. Combustion was described as very smooth, with very low cyclic variations. Noguchi et al. also conducted a spectroscopic study of $\mathrm{HCCl}$ combustion [2]. Many radicals were observed, and they were shown to appear in a specific temporal sequence. In contrast, with spark-ignited (SI) combustion all radicals appear at the same time (probably distributed in a specific spatial sequence through the flame front). These initial experiments were done in 2-stroke engines, with very high rates of EGR [2].

Since this early work [2, 3], two-stroke engines with $\mathrm{HCCl}$ operation over part of the load range have been developed to the point of commercialization for motorcycles [4]. $\mathrm{HCCl}$ motorcycle engines have higher fuel economy, lower emissions and smoother combustion than 2-stroke spark-ignited engines. However, $\mathrm{HC}$ and $\mathrm{CO}$ emissions out of the $\mathrm{HCCl}$ engine are still very high compared with the current automotive emissions standards. An improved version of the engine has been recently evaluated, which shows improvements in fuel economy and emissions [5].

In 1983, Najt and Foster did the first $\mathrm{HCCl}$ experiment with a four-stroke engine [6]. They also analyzed the process, considering that $\mathrm{HCCl}$ is controlled by chemical kinetics, with negligible influence from physical effects (turbulence, mixing). Najt and Foster used a simplified chemical kinetics model to predict heat release as a function of pressure, temperature, and species concentration in the cylinder. 
Later, in 1989, Thring studied four-stroke $\mathrm{HCCl}$ operation of Diesel fuel with varying intake temperature and EGR fraction over a range of equivalence ratio [7]. The Diesel fuelled $\mathrm{HCCl}$ engine achieved lower indicated specific fuel consumption than a direct injected Diesel compression ignition engine, although the energy for intake preheating was not accounted for in this assessment.

Researchers at the Lund Institute in Sweden have done a great deal of experimental work in four-stroke, singlecylinder, $\mathrm{HCCl}$ combustion [8-12]. These papers present extensive experimental results on fuel and operating parameters for a 2.2L/cylinder class $\mathrm{HCCl}$ engine. Operating and control parameters such as intake temperature, EGR, variable compression ratio, water injection, multiple fuels and fuel combinations have been studied for effects on the work output, emissions and combustion process parameters. This work has demonstrated the ability to operate $\mathrm{HCCl}$ engines over a wide range of load with low $\mathrm{NO}_{x}$ emissions when operating parameters are selected appropriately.

Recently the Lund group has operated a six-cylinder engine (in this case $1.95 \mathrm{~L} /$ cylinder) in $\mathrm{HCCl}$ mode[13]. The combustion process was adjusted using variable intake temperature and a dual-fuel configuration that allowed for variation of the fuel blend's autoignition characteristics (e.g. octane number). Engine speed was also varied. Brake Mean Effective Pressure (BMEP) between 1.5 and 6 bar was achieved and brake thermal efficiency ranged between 26 and $43 \%$. $\mathrm{NO}_{\mathrm{x}}$ emissions of under $20 \mathrm{mg} / \mathrm{kWh}$ were achieved up to 5 bar BMEP, but rose rapidly at higher load (up to $250-450 \mathrm{mg} / \mathrm{kWh}$. A typical Diesel has much higher $\mathrm{NO}_{\mathrm{x}}$ emissions, on the order of $4000 \mathrm{mg} / \mathrm{kW}-\mathrm{h}$ ). The control of combustion timing was a global process - individual cylinders were not adjusted independently [13].

$\mathrm{HCCl}$ experiments are also being explored for smaller displacement engines. Kimura et al. [14] use a novel direct injection scheme in a $0.49 \mathrm{~L}$ single-cylinder engine that results in the fuel and air mixture being relatively homogeneous before autoignition occurs. This work has demonstrated efficient operation under low-load conditions. Engines with small displacement per cylinder have unique challenges relative to larger displacement engines because of the heat transfer effect due to the typically higher ratio of combustion chamber surface area to volume, i.e. surface to volume ratio.

A description of the $\mathrm{HCCl}$ process has gained acceptance: $\mathrm{HCCl}$ has been described as controlled by chemical kinetics, with little effect of turbulence. Gasses in the crevices and boundary layers are too cold to react completely, and result in hydrocarbon and $\mathrm{CO}$ emissions. Combustion at homogeneous, low equivalence ratio ("Iean") conditions results in modest temperature combustion products, containing very low concentrations of $\mathrm{NO}_{x}$ and particulate matter.
Detailed chemical kinetic analysis of $\mathrm{HCCl}$ combustion for both propane and natural gas has given insight into the ignition process $[15,16]$. The decomposition of hydrogen peroxide $\left(\mathrm{H}_{2} \mathrm{O}_{2}\right)$ "triggers" the ignition. $\mathrm{H}_{2} \mathrm{O}_{2}$ accumulates due to low temperature reactions during the compression stroke. At temperatures in the range of $1050-1100 \mathrm{~K}$ the $\mathrm{H}_{2} \mathrm{O}_{2}$ decomposes rapidly into two hydroxyl $(\mathrm{OH})$ radicals, forming an enormous pool of $\mathrm{OH}$ radicals. This pool of radicals sets in motion a very effective chain branching sequence that rapidly consumes the fuel. Multi-zone analysis, which accounts for temperature non-uniformity along with the chemical kinetics, has shown that hydrocarbon and carbon monoxide emissions are due to the coupling of between the chemistry and the in-cylinder temperature distribution. In regions of lower temperature, an insufficient population of $\mathrm{OH}$ radicals is produced, resulting in incomplete or no conversion of the fuel.

Despite our physical understanding, challenges remain in a solution to the problems of operating a four-stroke engine in $\mathrm{HCCl}$ mode. The control issue appears to be most important. Some alternatives have been described [17-22], but further research is required to identify a general control strategy, even for control of singlecylinder engines. Multi-cylinder operation provides an added level of complexity to the $\mathrm{HCCl}$ engine control problem, because each cylinder may need independent control.

This paper seeks to investigate some of the basic operational characteristics of small displacement multicylinder engines. A modern automotive Diesel engine has been modified for operation as an $\mathrm{HCCl}$ engine. In this case a Volkswagen TDI engine was modified minimally to operate as propane fueled $\mathrm{HCCl}$ engine. This study investigates two basic parameters, fuel flow rate and intake manifold temperature, for their influence on the combustion process as well as the overall performance of the engine. By understanding how a baseline engine operates, some of the design issues that may improve $\mathrm{HCCl}$ operation in this class of engine can be identified.

\section{EXPERIMENTAL SETUP}

A Volkswagen TDI engine has been selected as the base engine for development and testing of an automotive-class $\mathrm{HCCl}$ engine applicable to conventional or hybrid power trains. The TDI engine is a four-cylinder turbocharged direct injection diesel engine. This engine has attributes appropriate for an automotive $\mathrm{HCCl}$ engine: $1.9 \mathrm{~L}$ displacement, high compression ratio, and ability to withstand high peak pressure. Table 1 lists engine specifications. The in-cylinder fuel injectors have been removed from the combustion chamber and have been replaced with inserts containing water-cooled quartz pressure transducers. The combustion chamber has not been modified otherwise - the stock pistons containing the reentrant bowl, shown in figure 1, have been retained for this current work. Figure 1 also shows the head and the block. The piston crown sits slightly 
above the level of the block at TDC, so the head gasket provides all the clearance height. Figure 2 shows the motoring pressure traces for the four cylinders operating at $1800 \mathrm{rpm}$. The engine BMEP is reported along with net IMEP for each cylinder. These IMEPs indicate significant heat transfer during motoring, suggesting heat transfer will be significant during firing operation. The differences in the motoring peak pressure between cylinders during motoring could be due to variations in compression ratio.

Table 1 - Engine parameters

\begin{tabular}{|l|l|}
\hline Displacement (all 4 cylinders) & $1.896 \mathrm{~L}$ \\
\hline Bore & $79.5 \mathrm{~mm}$ \\
\hline Stroke & $95.5 \mathrm{~mm}$ \\
\hline Connecting Rod & $144 \mathrm{~mm}$ \\
\hline Compression Ratio & $19: 1$ \\
\hline Intake Valve Open (1 mm lift) & $16^{\circ}$ ATDC \\
\hline Intake Valve Close (1 mm lift) & $25^{\circ}$ ABDC \\
\hline Exhaust Valve Open (1 mm lift) & $28^{\circ}$ BBDC \\
\hline Exhaust Valve Close (1 mm lift) & $19^{\circ}$ BTDC \\
\hline
\end{tabular}

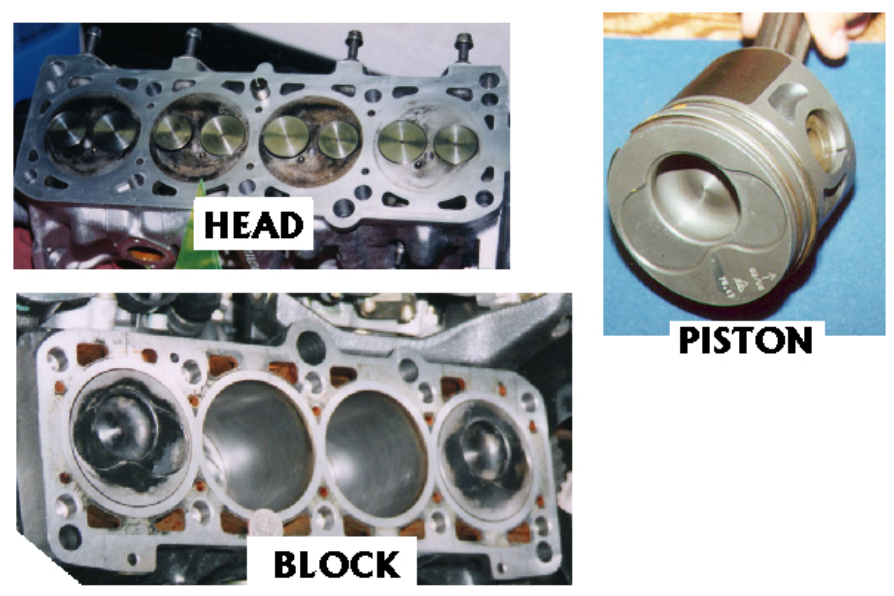

Figure 1 - Head, block (pistons at 1 and 4 at TDC, 2 and 3 at BDC), and a piston for VW TDI used for these tests.

Figure 3 shows a schematic of the experimental setup. The inducted air flow rate is measured with an orifice plate. Fuel flow is measured using an electronic mass flow meter. Uncertainty in the fuel flow rate measurement contributes \pm 0.02 maximum absolute error in equivalence ratio. The air is then heated with an electric heater, followed by fuel addition upstream of the intake manifold. The intake and exhaust have been modified by removal of the turbocharger, but the intake and exhaust manifolds have been retained. The fuel-air mixture is inducted into the engine and the combustion process is monitored with the four in-cylinder pressure transducers. A $3600 /$ rev shaft encoder is used to trigger the pressure acquisition. A small amount of the exhaust is diverted to the emissions analyzer for measurement of $\mathrm{THC}, \mathrm{CO}$, and $\mathrm{NO}_{\mathrm{x}}$ emissions.

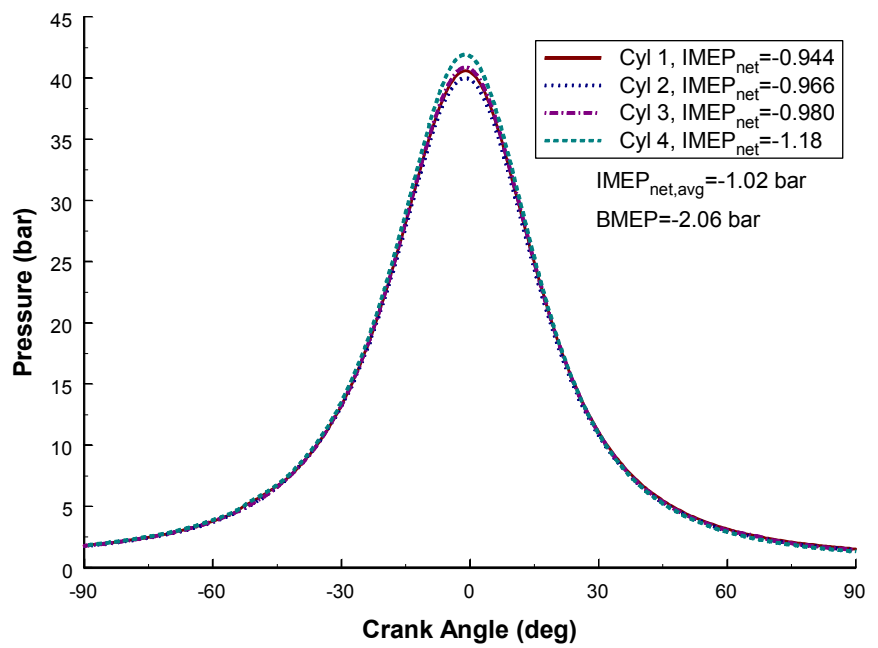

Figure 2 - Motoring pressure traces for individual cylinders in TDI engine. Net IMEP is reported for each cylinder, along with the average net IMEP of the four cylinders and BMEP

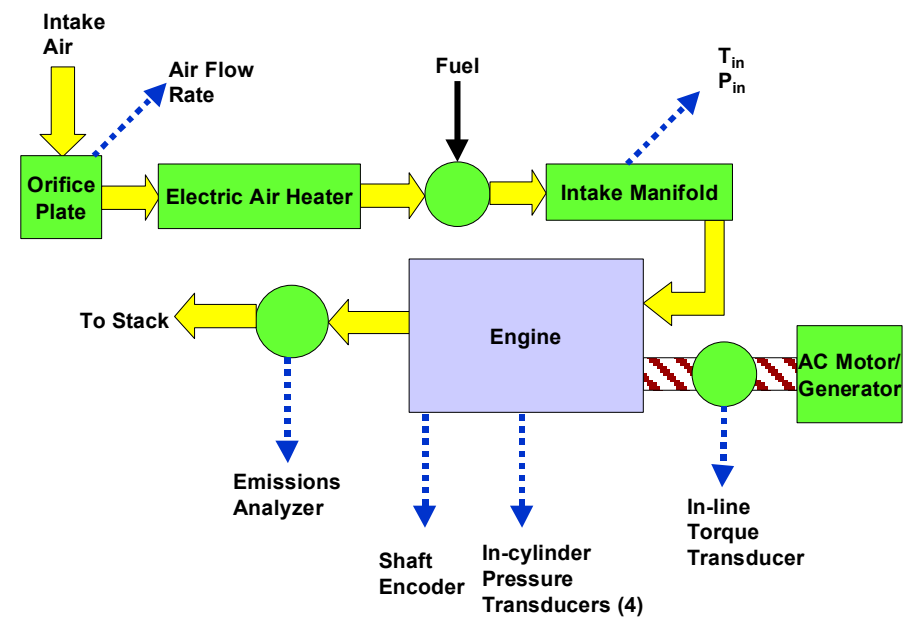

Figure 3 - Schematic of experimental setup

A $30 \mathrm{~kW}$ (40 hp) AC induction motor/generator is coupled to the engine. The electric motor/generator operates at a nominal speed of $1800 \mathrm{rpm}$. The motor is direct coupled to the engine so the ability to operate at other motor speeds is not currently available. Because of the asynchronous operation of induction motors, the engine rotational speed is slightly lower or higher than $1800 \mathrm{rpm}$ when acting as a motor or generator, respectively. This variation from nominal operating speed typically is $\pm 5 \mathrm{rpm}$. The engine output torque is measured with an inline torque transducer.

In this paper variation in intake mixture temperature and fuel flow rate on the engine operation is studied. For several fixed fuel flow rates the intake manifold temperature is varied. For a given fuel flow rate the lower limit of operation is specified by the temperature at which at least one cylinder misfires. Because $\mathrm{HCCl}$ combustion is so sensitive to temperature, slight 
variations in the conditions of each cylinder can result in one cylinder firing very well while at the same time, another cylinder misfires. As the intake temperature is further raised, the combustion timing becomes increasingly advanced relative to TDC and severe pressure oscillations occur. In these cases, heat transfer to the water and oil appears to become very large, causing the water temperature to rise rapidly and the oil pressure to drop precariously. Operation in these regimes could be damaging to the engine and is therefore avoided.

\section{RESULTS}

Experiments have been conducted for naturally aspirated operation with propane fuel. The engine performance, combustion process, and emissions are monitored for variations in intake temperature and fuel flow rate. The intake temperature ranges from roughly $105^{\circ} \mathrm{C}$ to $145^{\circ} \mathrm{C}$. Five different fuel flow rates have been studied: $0.34 \mathrm{~g} / \mathrm{s}$, $0.50 \mathrm{~g} / \mathrm{s}, 0.65 \mathrm{~g} / \mathrm{s}, 0.72 \mathrm{~g} / \mathrm{s}$, and $0.83 \mathrm{~g} / \mathrm{s}$. The next sections will discuss the performance of the overall engine and individual cylinders.

OVERALL PERFORMANCE - Figure 4 shows intake equivalence ratio versus intake manifold temperature for the conditions tested. The equivalence ratio is determined from the measured intake air and fuel flow rates. The equivalence ratio ranges from 0.2 to 0.55 for these conditions.

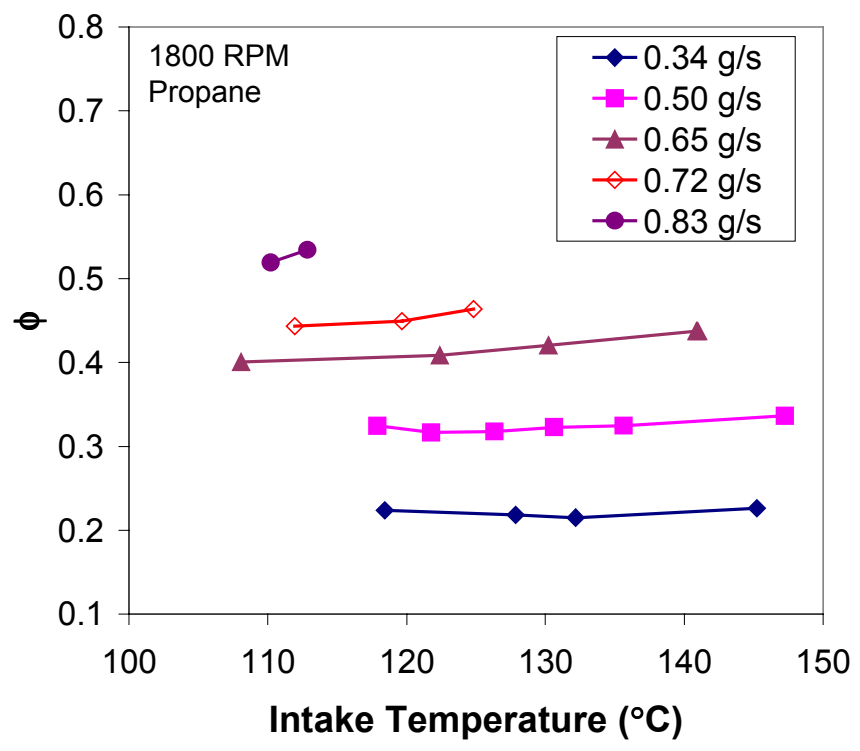

Figure 4 - Intake equivalence ratio versus intake manifold temperature, for several fuel flow rates.

The combustion efficiency has been determined from the exhaust emissions using the textbook procedure of Heywood [23] that accounts for conversion and partial conversion of the inducted fuel. Figure 5 shows combustion efficiency versus intake temperature. The combustion efficiency tends to increase as fuel flow rate increases at constant temperature or as temperature is increased at constant fuel flow rate. For the lowest fuel flow rate case, the combustion efficiency is very poor, yielding less than $60 \%$ efficiency at the lowest temperature. In this extreme case (lowest intake temperature, lowest fuel flow rate) all cylinders are firing with relative consistency, as seen in figure 6 , but this is a very poor operating point because the combustion efficiency in each cylinder is consistently low. In contrast to this, the lowest temperature operating point at $0.65 \mathrm{~g} / \mathrm{s}$ fuel flow rate shows significant differences in the operation of each cylinder, as seen in figure 7 . These results will be discussed in more detail in a later section, but are presented for preliminary explanation and to demonstrate some of the challenges of multi-cylinder $\mathrm{HCCl}$ engine operation.

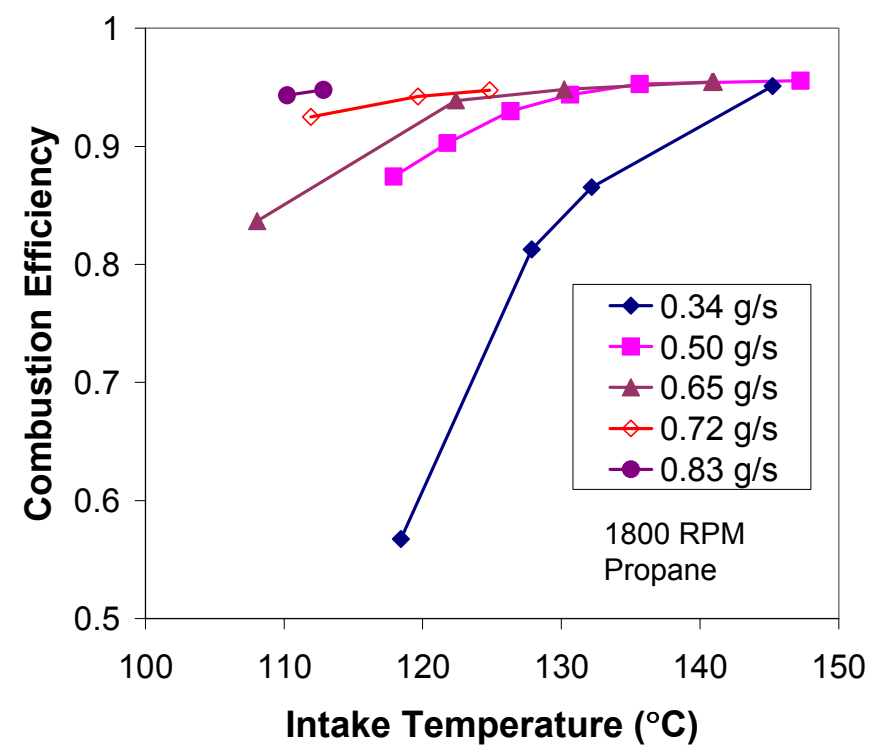

Figure 5 - Combustion efficiency based on exhaust emissions versus intake manifold temperature
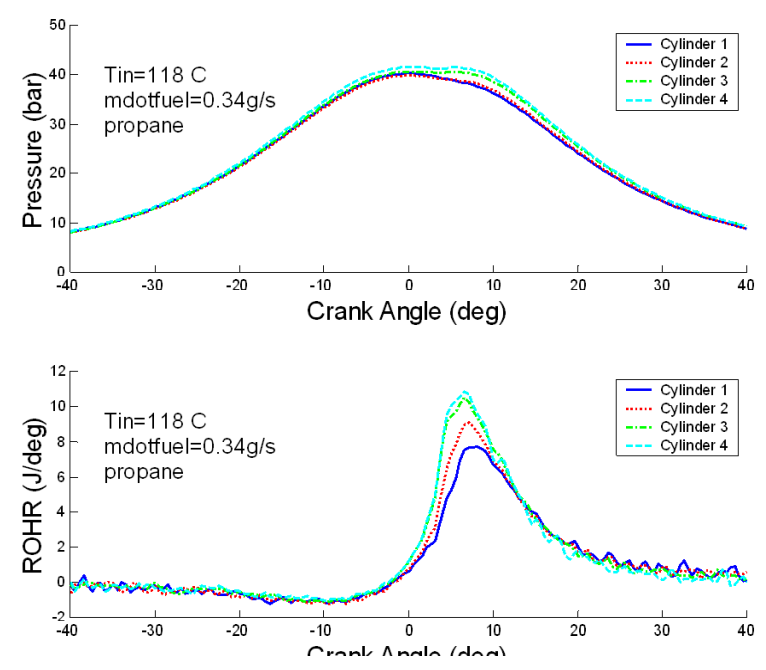

Figure 6 - Pressure trace and calculated rate of heat release for the lowest fuel flow rate, $0.34 \mathrm{~g} / \mathrm{s}$, and lowest intake temperature 
Total hydrocarbon emissions (THC), carbon monoxide (CO) and $\mathrm{NO}_{\mathrm{x}}$ emissions are shown in figures 8,9 , and 10 respectively. All emissions are normalized by the fuel mass flow in order to have a common basis for comparison between operating conditions. The hydrocarbon emissions are very closely related to the combustion efficiency, albeit inversely. The trends show is that as the fuel flow rate or intake temperature increases the hydrocarbon emissions decreases. The $\mathrm{CO}$ emissions follow the same pattern. The trend in $\mathrm{NO}_{x}$ emissions is to increase with increasing fuel flow rate at constant temperature or increasing temperature at constant fuel flow rate. At the lowest fuel flow rates (0.34 $\mathrm{g} / \mathrm{s}$ and $0.50 \mathrm{~g} / \mathrm{s}$ ) the $\mathrm{NO}_{\mathrm{x}}$ is very low (less than $5 \mathrm{ppm}$ $\mathrm{NO}_{\mathrm{x}}$ ), so the crossover seen may be due to the precision of the $\mathrm{NO}_{x}$ analyzer.
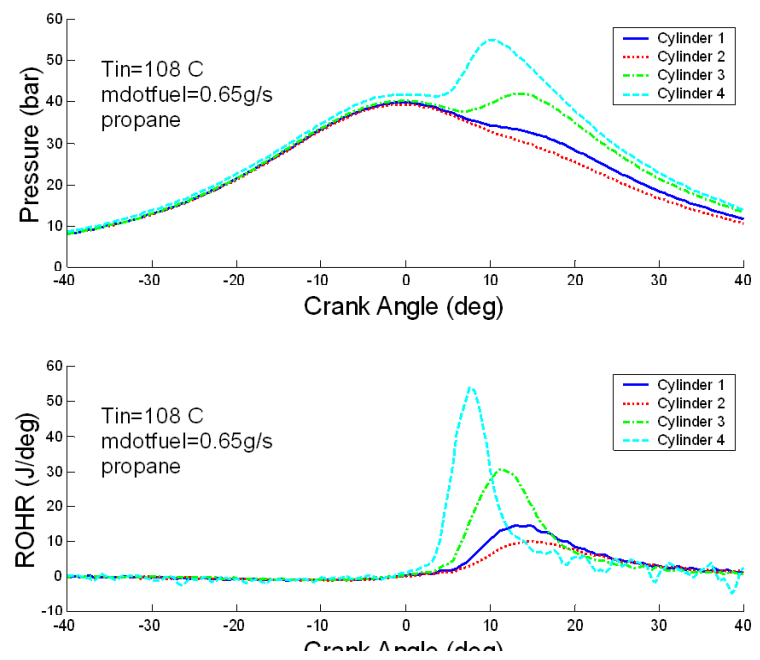

Figure 7 - Pressure trace and calculated rate of heat release for a fuel flow rate of $0.65 \mathrm{~g} / \mathrm{s}$ and the lowest intake temperature.

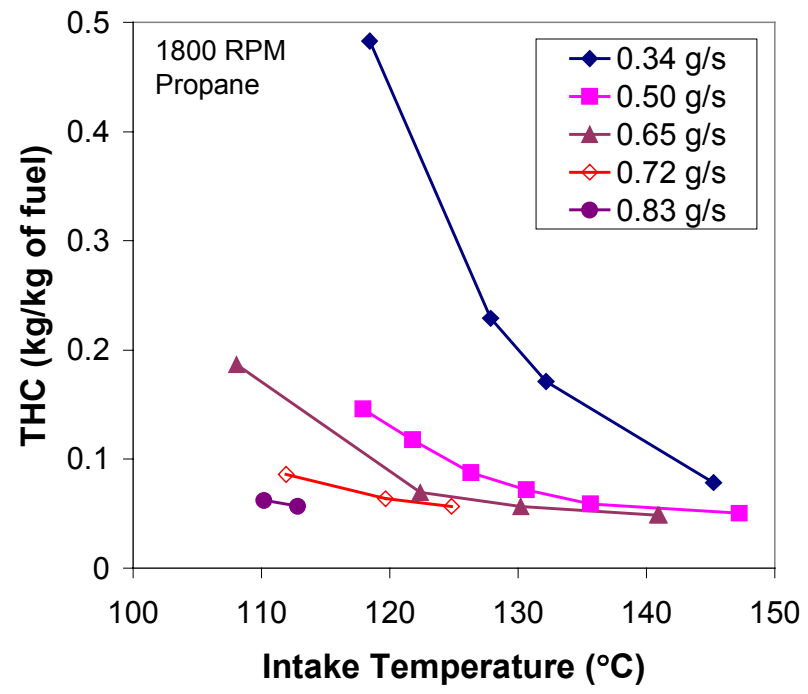

Figure 8 - Total hydrocarbon emissions versus intake manifold temperauture

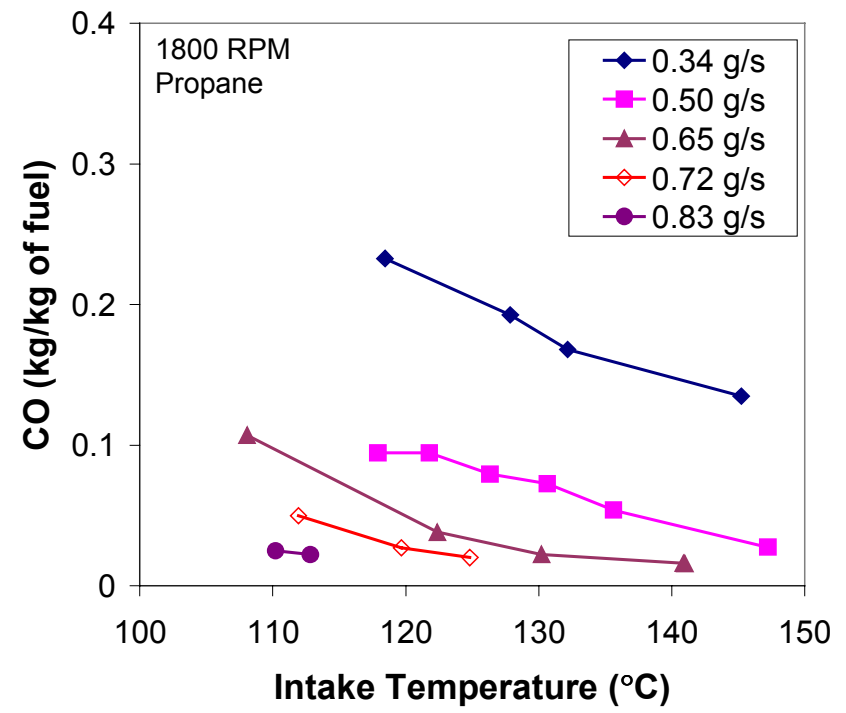

Figure 9 - Carbon monoxide emissions versus intake manifold temperature

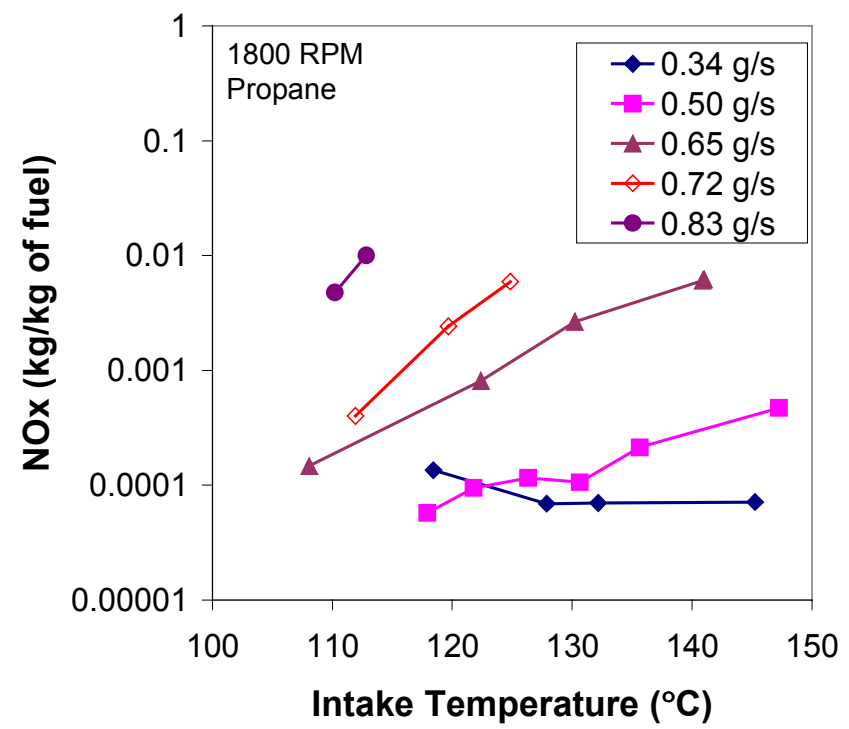

Figure 10 - Oxides of nitrogen emission versus intake manifold temperature

Figure 11 shows the brake mean effective pressure (BMEP) versus intake manifold temperature. The BMEP ranges from -0.8 bar to 3.3 bar for this operating range. The idle (0 bar BMEP) operating point occurs at $0.34 \mathrm{~g} / \mathrm{s}$ fuel flow rate and an intake temperature of roughly 130 ${ }^{\circ} \mathrm{C}$. Referring back to figure 5 , the combustion efficiency at this idle operating point is around $75 \%$. The THC and $\mathrm{CO}$ emissions for this point may be unacceptably high. It may be possible to improve combustion efficiency by going to a lower fuel flow rate and a higher intake temperature. For the high load operating points, the trend is that lower intake temperature results in higher 
BMEP. Ignoring the lowest temperature operating point for $0.65 \mathrm{~g} / \mathrm{s}$ fuel flow rate (which is relatively unstable), the three highest fuel flow rates, $0.65,0.72$, and $0.83 \mathrm{~g} / \mathrm{s}$ have the same trend. The brake thermal efficiency, average net indicated efficiency, and average gross indicated efficiency are shown in figures 12-14, respectively, for all fuel flow rates. These indicated efficiencies are calculated based on the average of the work per cycle for all four cylinders. The brake thermal efficiency ranges from less than zero (negative efficiency meaning that work must be added to the engine by the electric motor to sustain operation) to $25 \%$. The maximum gross indicated thermal efficiency is $32 \%$. The indicated efficiency is low despite the high compression ratio, likely due to a combustion chamber design (high swirl, very little clearance between the piston top and head at TDC) that results in significant heat transfer. Figure 15 shows the brake, average net indicated, and average gross indicated mean effective pressure for 0.65 $\mathrm{g} / \mathrm{s}$ fuel-flow rate. For all operating points the difference between the net IMEP and BMEP ranges from 0.85 to 0.9 bar.

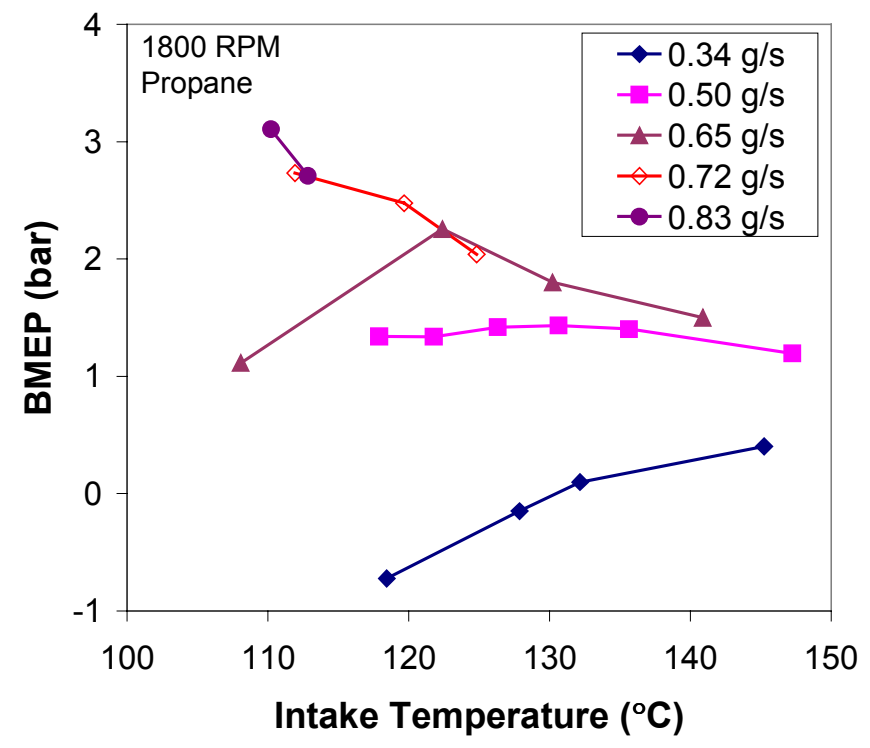

Figure 11 - BMEP versus intake manifold temperature

A problem that will likely need to be overcome in order to generate higher efficiency and BMEP with a multicylinder $\mathrm{HCCl}$ engine is the variations in performance between the cylinders. For instance, figures 16 and 17 show the gross IMEP for each cylinder versus intake temperature for 0.34 and $0.83 \mathrm{~g} / \mathrm{s}$ fuel flow rates, respectively. The IMEP of each cylinder varies considerably between the cylinders. The trends are not completely consistent (i.e. the IMEP for cylinder 2 is not always higher than cylinder 1), suggesting that multiple factors play a role: non-uniformity in the intake manifold temperature, small variations in compression ratio between the cylinders, variations in combustion chamber wall temperatures, exhaust gas residuals, etc. As will be shown in the next section, the combustion phasing is different between the cylinders for the same intake manifold temperature. This can lead to a situation where some cylinders can be in stable operation and others misfire. Balancing the cylinders so that all cylinders have optimum combustion timing for a specific load will allow for better overall engine performance. The cylinder balancing process would likely require a feedback control mechanism for each cylinder.

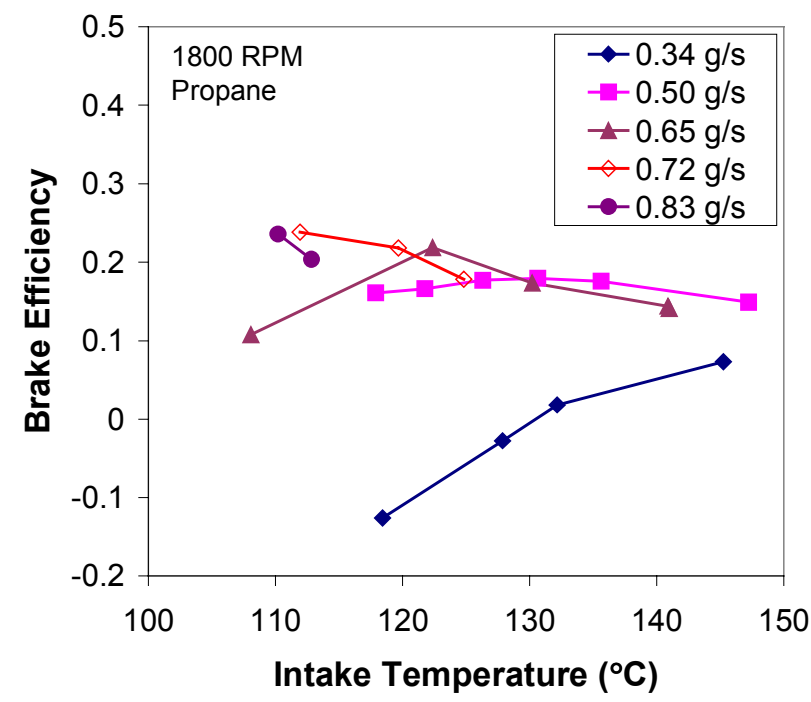

Figure 12 - Brake efficiency versus intake manifold temperature

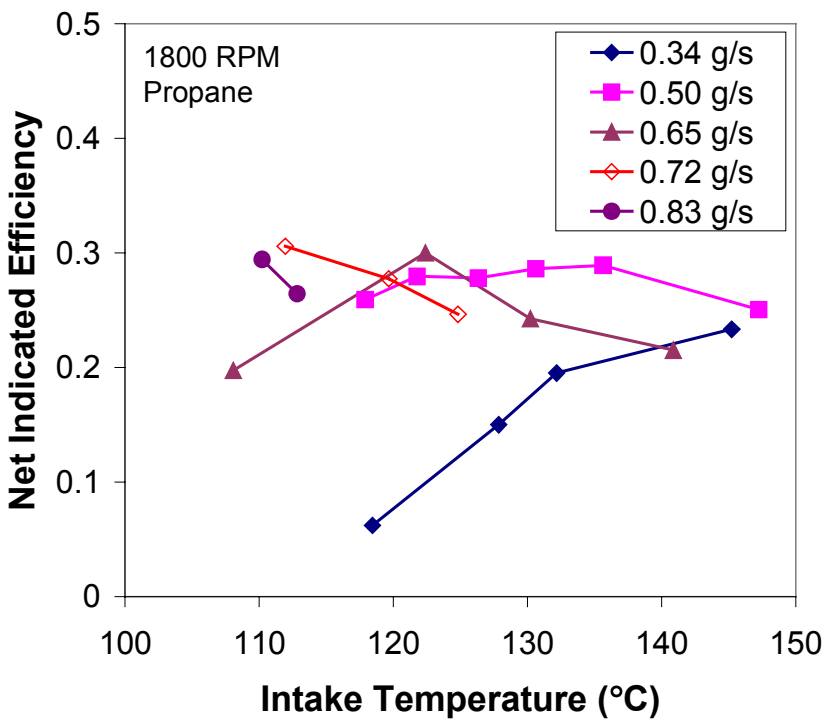

Figure 13 - Net indicated efficiency (average of the four cylinders) versus intake manifold temperature.

CYLINDER-BY-CYLINDER - At each operating condition the performance of each cylinder can vary significantly. We will use results for the $0.65 \mathrm{~g} / \mathrm{s}$ fuel-flow rate case to illustrate cylinder by cylinder operation. The individual cylinder data is plotted versus intake temperature or combustion timing. Figure 18 shows a sample plot of 
rate of heat release versus crank angle for propane $\mathrm{HCCl}$ combustion. The rate of heat release presented is chemical heat release determined by analysis of the pressure trace [23].

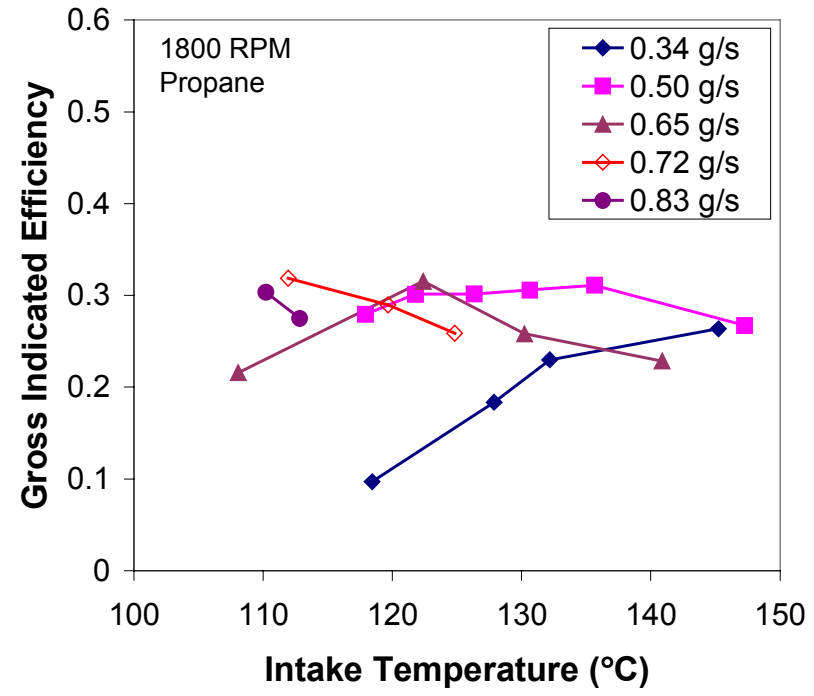

Figure 14 - Gross indicated efficiency (average of the four cylinders) versus intake manifold temperature.

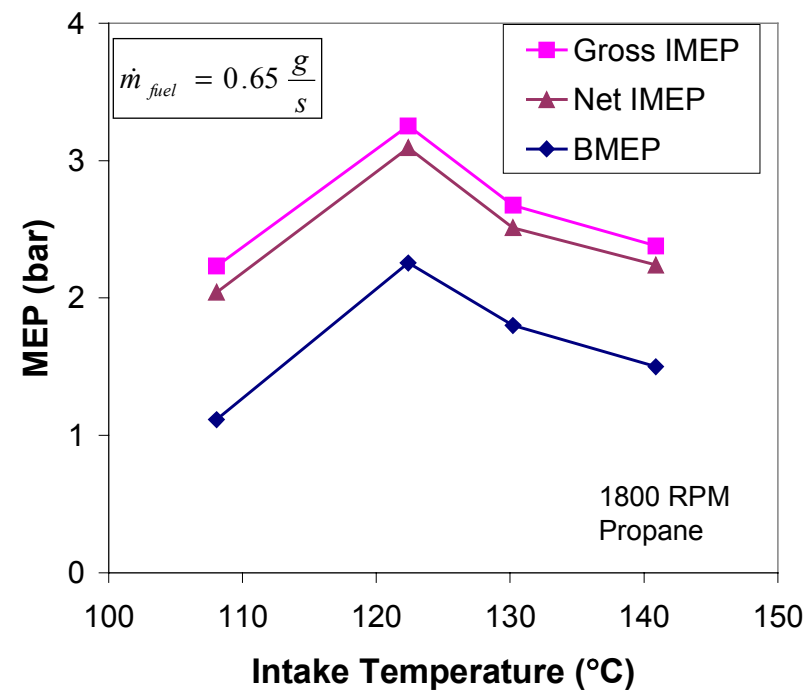

Figure 15 - Brake, net indicated, and gross indicated thermal efficiency versus intake temperature for $0.65 \mathrm{~g} / \mathrm{s}$ fuel flow rate. Indicated efficiencies are averages from all four cylinders.

The combustion timing and burn duration used in this paper are defined based upon the characteristics of the heat release curve. The crank angle corresponding to the peak of the rate of heat release (POHR) is used as the marker of combustion timing. The crank angle that corresponds to $10 \%$ of the peak rate of heat release on the rising edge of the rate of heat release curve is specified as the start of combustion (SOC). Similarly the "end" of combustion is specified as the crank angle corresponding to $10 \%$ of the peak heat release rate on the falling edge of the curve. The difference in crank angle between the start of combustion and end of combustion is the burn duration. The falling edge of the heat release curve can be very noisy due to acoustic phenomena in the cylinder (knock-like pressure oscillations). To compensate for this, a Gaussian exponential function is fitted to the falling edge and is used to average these oscillations. The smoothed curve is used for determining burn duration.

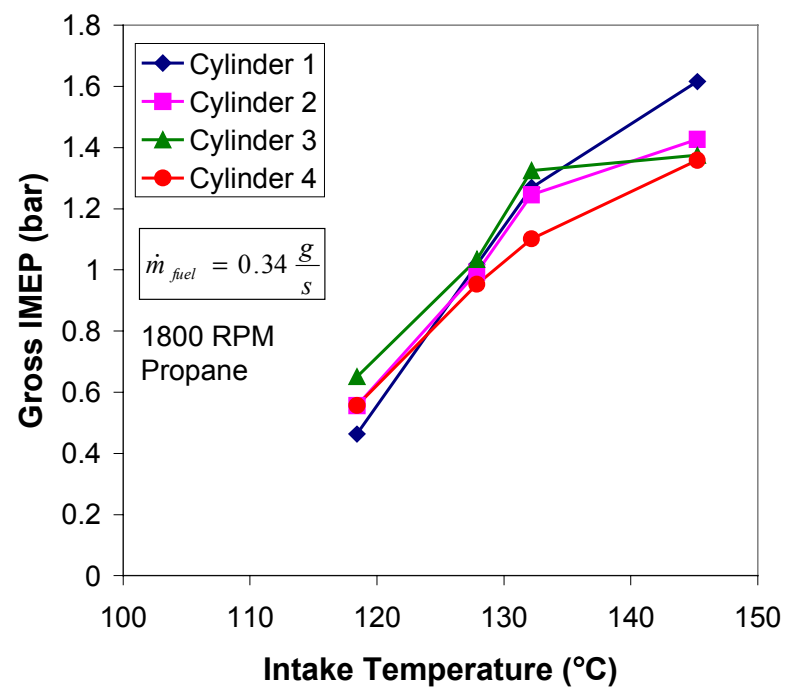

Figure16- Gross IMEP for each cylinder versus intake manifold temperature for $0.34 \mathrm{~g} / \mathrm{s}$ fuel flow rate

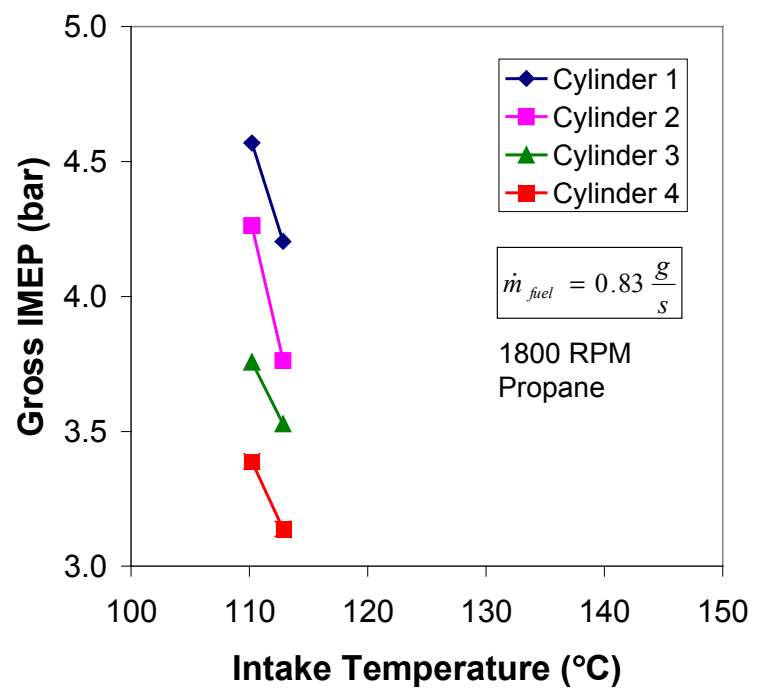

Figure 17 - Gross IMEP for each cylinder versus intake manifold temperature for $0.83 \mathrm{~g} / \mathrm{s}$ fuel flow rate

Figures 19 and 20 show pressure traces and rate of heat release (ROHR) traces for each cylinder at four different intake manifold temperatures at $0.65 \mathrm{~g} / \mathrm{s}$ fuel flow rate. 
The pressure traces are an average of 332 instantaneous traces and ROHR is determined from this average. The lowest temperature operating point, $108^{\circ} \mathrm{C}$ intake temperature, operation can be seen to be very inconsistent between the cylinders. Operation around the lower limits is very tenuous, and the difference between stable operation and misfire requires only a small change in the control parameters [24]. Slight variations in cooling water temperature, oil temperature, compression ratio of each cylinder, intake manifold temperature inhomogeneities could result in significant variations in the combustion process. For example, in the VW TDI engine the cooling water runs longitudinally through the engine entering near cylinder 1 and exiting at cylinder 4 . This could result in a higher water temperature gradient along the engine, resulting in variations in heat transfer throughout the engine. The $108^{\circ} \mathrm{C}$ operating point may be near the lower limit of operation, and the slight differences in the parameters mentioned above could explain this inconsistent operation.

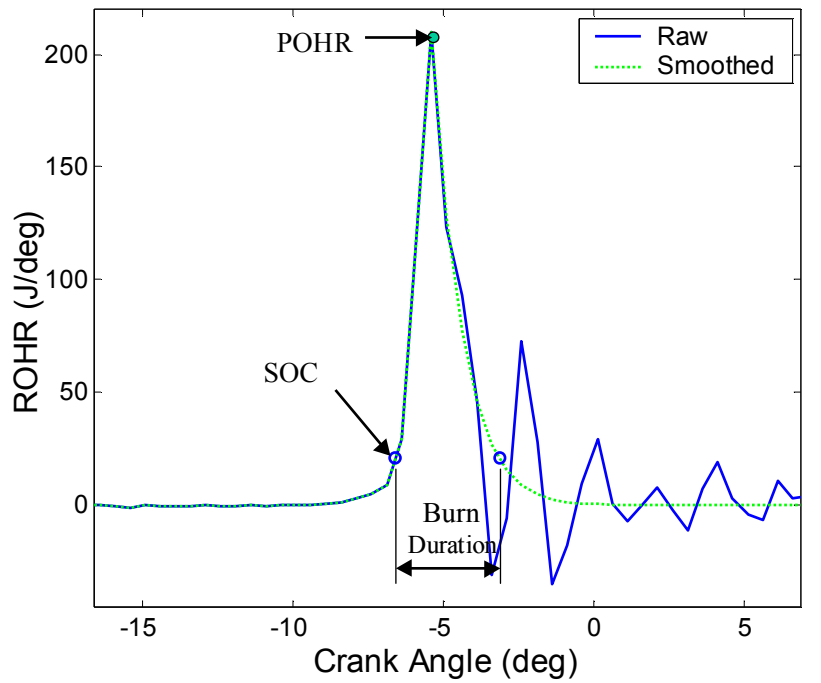

Figure 18 - Rate of heat release versus crank angle. The falling side of the curve is smoothed by Gaussian fitting. Start of combustion (SOC) is specified crank angle corresponding to $10 \%$ of the magnitude of peak of heat release (POHR) on the rising side of the curve. Burn duration is the distance between the SOC crank angle and the crank angle coressponding to $10 \%$ of the peak of heat release on the falling side of the curve, using the smoothed curve.

Figures 19 and 20 show that as the intake temperature is increased the combustion process becomes more consistent among the cylinders. Figure 21 shows the combustion timing defined as the peak rate of heat release (POHR) plotted against intake manifold temperature for each of the four cylinders. At the lowest temperature the spread in timing between cylinders is 7 CAD, but for the higher intake temperatures operating points the spread is consistently about 2 CAD. As expected, the timing advances for each cylinder as intake temperature increases. The trend in POHR between cylinders is not particularly consistent. For instance, cylinder 2 fires latest in the lowest temperature case, but cylinder 1 fires latest in the other cases. These results show that controlling individual cylinders requires a strategy strong enough to overcome a variety of operating factors.
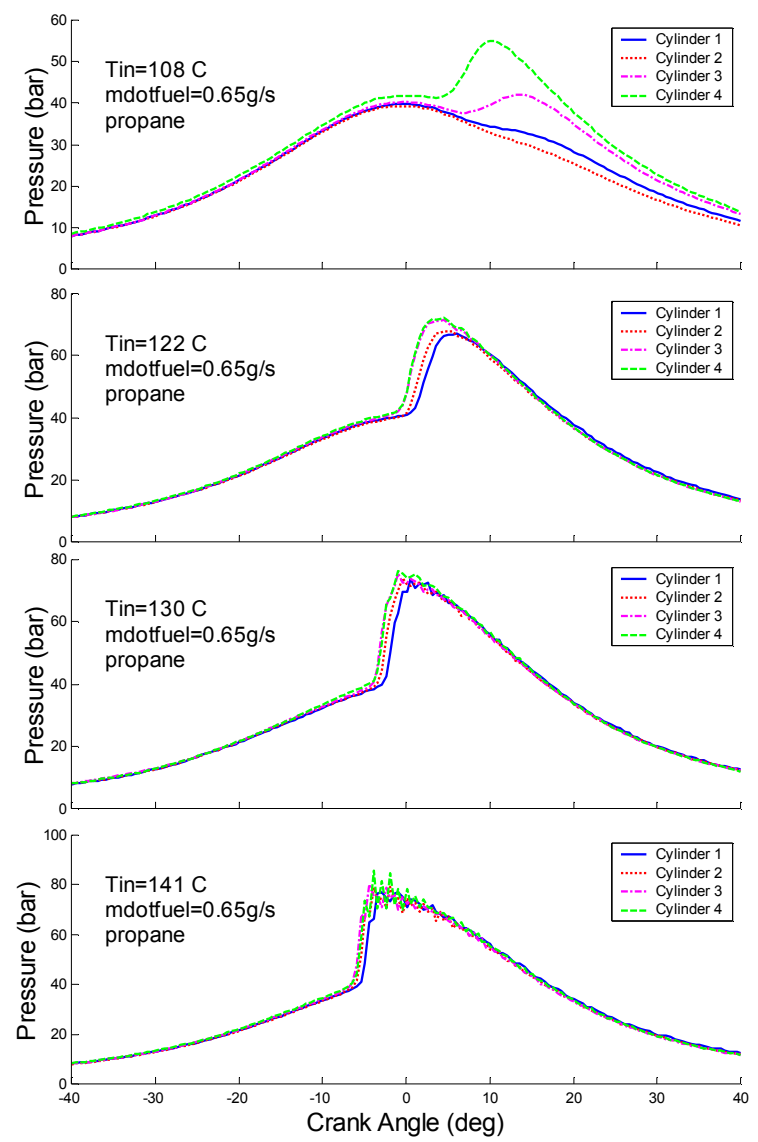

Figure 19 - Pressure traces for four different intake manifold temperatures at $0.65 \mathrm{~g} / \mathrm{s}$ fuel flow rate (average of 332 instantaneous traces).

Figure 22 shows burn duration for each cylinder plotted versus intake manifold temperature. The spread in burn duration is very wide at the low temperature operating point (10 CAD) and the spread reduces to 2.5 degrees for the other temperatures. As intake temperature increases in the two highest temperature cases, the variation in burn duration decreases. The combustion timing in figure 21 also decreases for these cases. Figure 23 shows the burn duration versus the POHR combustion timing. The correlation of burn duration relative to combustion timing is good for early timed cases and poor for later timed cases. The late timing case for each cylinder corresponds to the lowest temperature operating point where very inconsistent combustion occurs in the four cylinders.

Figure 24 shows the gross IMEP versus POHR combustion timing for each of the four cylinders. The main conclusion that can be drawn from this figure is that the IMEP has a somewhat consistent trend with respect to peak of heat release between cylinders although there is a great deal of spread. Figure 25 shows peak cylinder pressure versus POHR timing and the trend shown is 
that later timing reduces peak cylinder pressure in all cylinders.

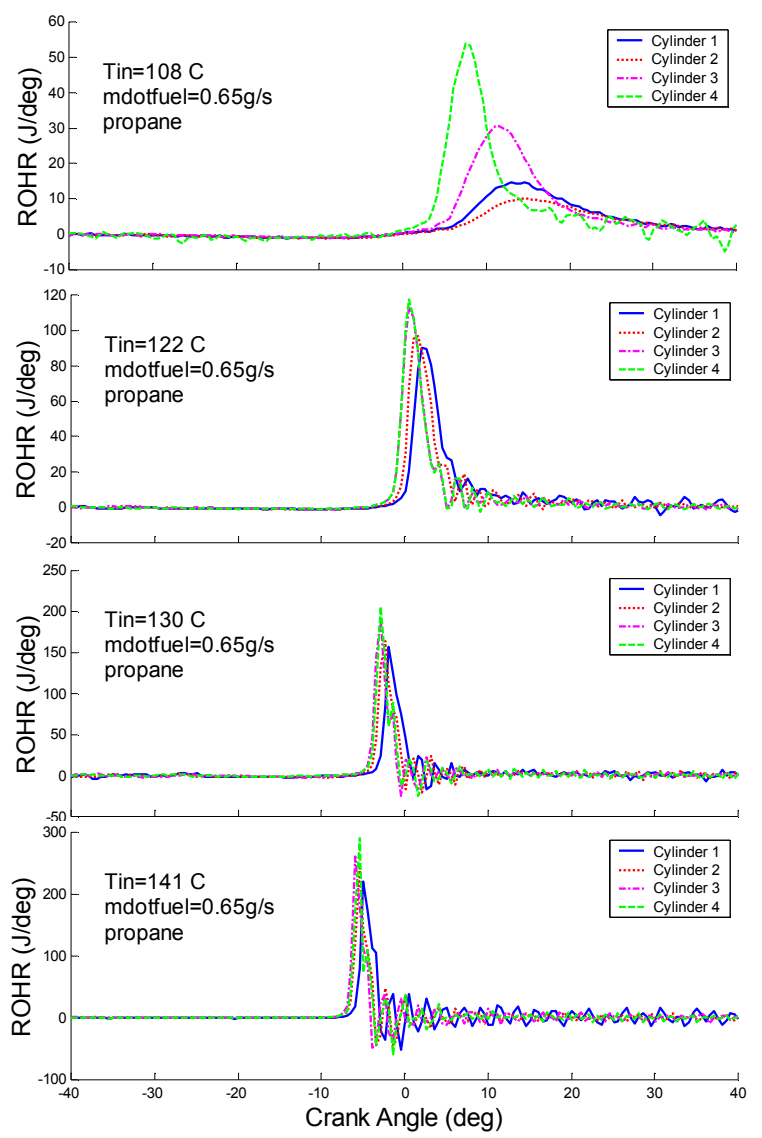

Figure 20 - Rate of heat release traces for four different intake manifold temperatures at $0.65 \mathrm{~g} / \mathrm{s}$ fuel flow rate.

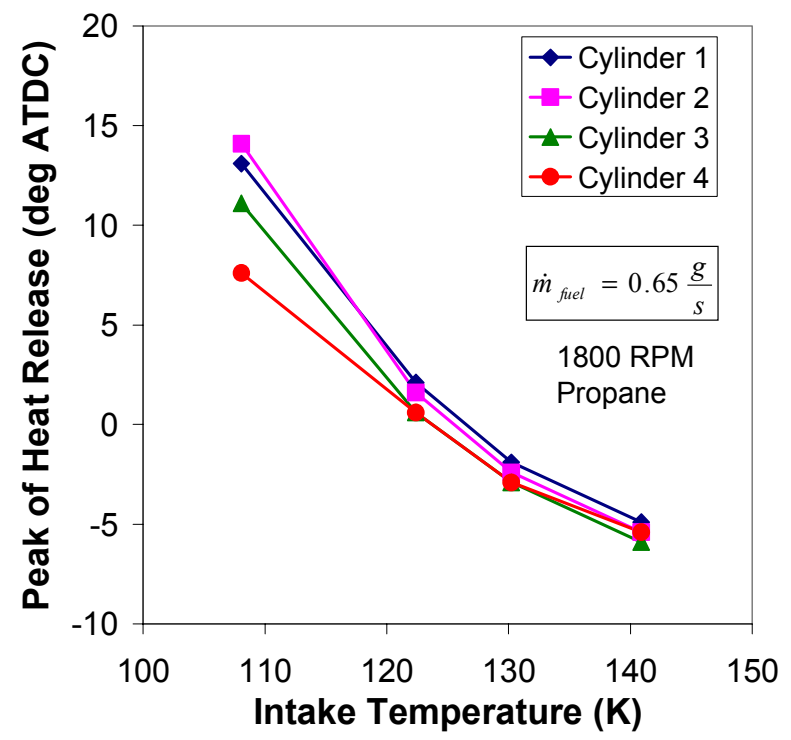

Figure 21 - Timing of peak of heat release rate versus intake temperature for $0.65 \mathrm{~g} / \mathrm{s}$ fuel flow rate.

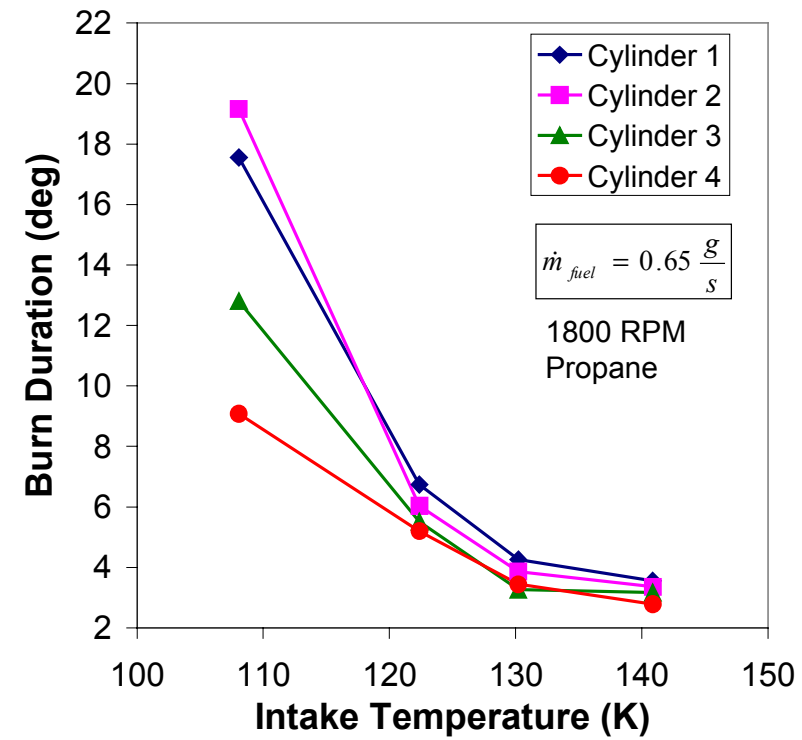

Figure 22 - Burn duration versus intake manifold temperature for each cylinder at $0.65 \mathrm{~g} / \mathrm{s}$ fuel flow rate.

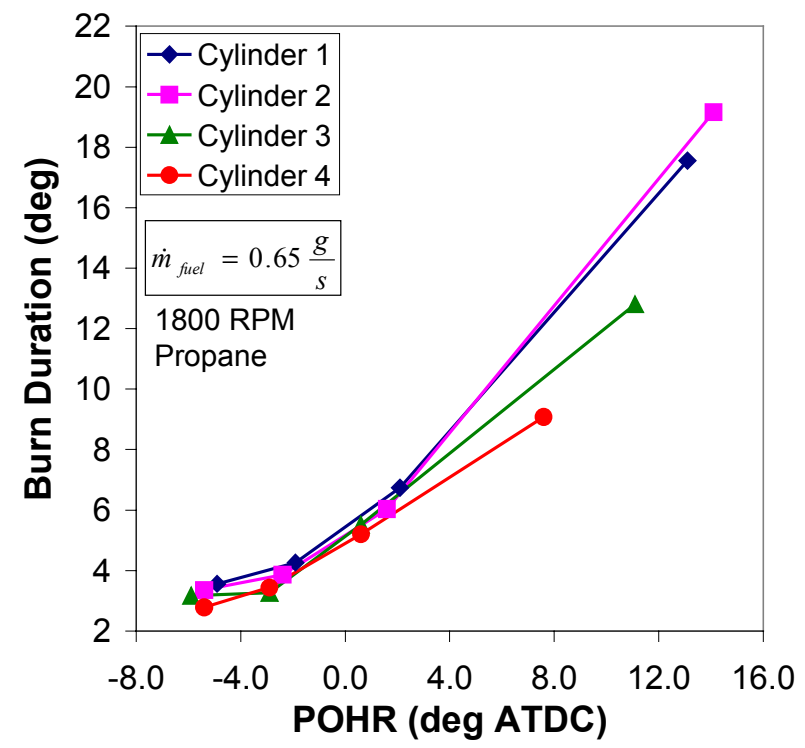

Figure 23 - Burn duration versus peak of heat release rate combustion timing for each cylinder at $0.65 \mathrm{~g} / \mathrm{s}$ fuel flow rate. 


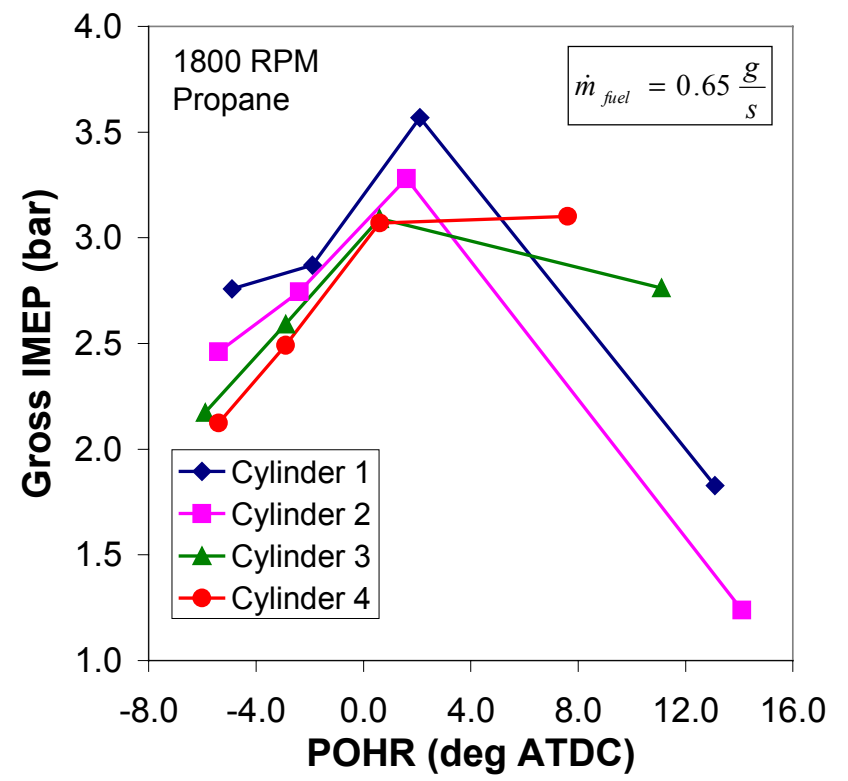

Figure 24 - Gross Indicated Mean Effective Pressure versus peak of heat release rate combustion timing for each cylinder at $0.65 \mathrm{~g} / \mathrm{s}$ fuel flow rate.

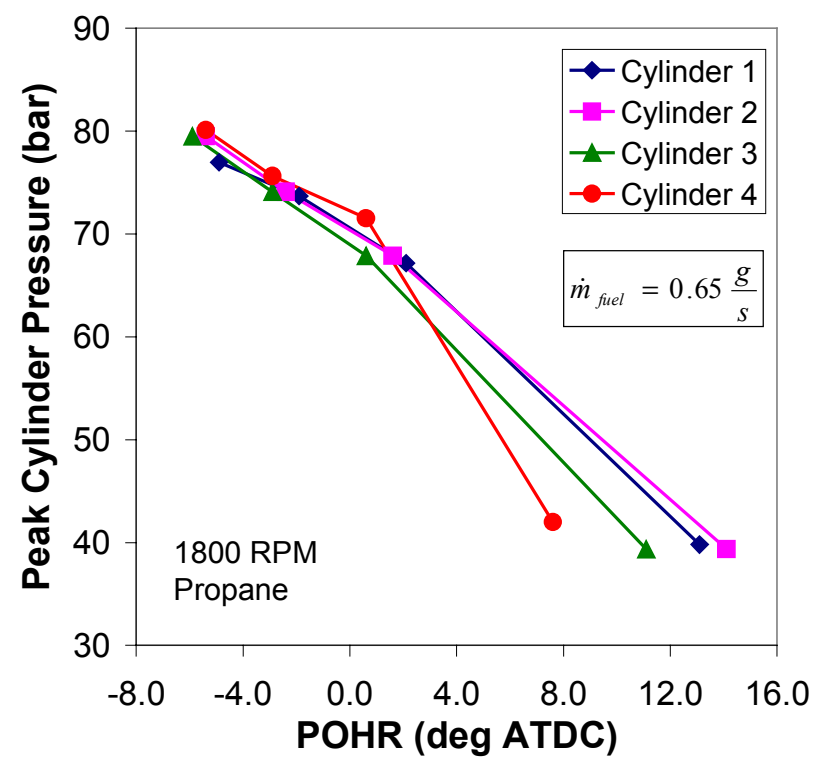

Figure 25 - Gross Indicated Mean Effective Pressure versus peak of heat release rate combustion timing for each cylinder at $0.65 \mathrm{~g} / \mathrm{s}$ fuel flow rate.

\section{CONCLUSIONS}

- Operation from idle conditions to slightly over 3 bar BMEP has been achieved. The highest power output operating point tends to be approached as intake temperature is lowered and fuel flow rate is increased. A difference in combustion timing between the cylinders may be responsible for the inability to achieve higher BMEP. It is suspected that the current Diesel combustion chamber design promotes significant heat transfer (high swirl, unfavorable surface to volume ratio, very small clearance between much of the piston top and the head at TDC). High heat transfer could explain the relatively low peak indicated efficiency $(32 \%)$ for this engine.

- Specific emissions of hydrocarbons and carbon monoxide (mass flow of emissions relative to mass flow of fuel inducted) tend to decrease with increasing intake temperature or increasing fuel flow rate.

- At a specific intake manifold temperature the combustion timing for each cylinder can vary widely. At the lowest temperatures one cylinder can be firing very well while another may be not firing at all due to variations between the cylinders. When looking at a constant fuel flow rate the trend in combustion timing is not necessarily consistent (i.e. cylinder 4 will not always be the most advanced in timing as intake temperature increases).

- When viewing the data with respect to combustion timing, the trends in burn duration, and peak cylinder pressure appear to correlate well. The overall trend in IMEP seems relatively consistent between the cylinders, but the spread in values at particular combustion timing is large. Variations between the cylinders such as individual cylinder intake temperature, compression ratio, wall temperature, etc. are proposed as possible factors that could contribute to the variation in IMEP.

- Key to further improving performance of the engine is controlling individual cylinder combustion timing. Minimizing phasing differences between the cylinders is likely necessary to achieve higher BMEP.

\section{ACKNOWLEDGMENTS}

This project is funded by DOE Office of Heavy Vehicle Technology, Steve Goguen and Gurpreet Singh, Program Managers. Work performed under the auspices of the U.S. Department of Energy by University of California Lawrence Livermore National Laboratory under Contract W-7405-ENG-48.

\section{REFERENCES}

1. Suzuki, H., Koike, N., Ishii, H. and Odaka, M., 1997, "Exhaust Purification of Diesel Engines by Homogeneous Charge with Compression Ignition Part 1: Experimental Investigation of Combustion and Exhaust Emission Behavior Under Pre-Mixed Homogeneous Charge Compression Ignition Method," SAE paper 970313.

2. Noguchi, M., Tanaka, Y., Tanaka, T. and Takeuchi, Y., 1979, "A Study on Gasoline Engine Combustion by Observation of Intermediate Reactive Products During Combustion," SAE paper 790840.

3. Onishi, S., Jo, S.H., Shoda, K., Jo, P.D. and Kato, S., 1979, "Active Thermo-Atmosphere Combustion 
(ATAC) - A New Combustion Process for Internal Combustion Engines," SAE paper 790501.

4. Ishibashi, Y. and Asai, M., 1996, "Improving the Exhaust Emissions of Two-Stroke Engines by Applying the Activated Radical Concept," SAE Paper 960742.

5. Ishibashi, Y. and Asai, M., 1998, "A Low Pressure Pneumatic Direct Injection Two-Stroke Engine by Activated Radical Combustion Concept," SAE Paper 980757.

6. Najt, P.M. and Foster, D.E., 1983, "CompressionIgnited Homogeneous Charge Combustion," SAE paper 830264.

7. Thring, R.H., 1989, "Homogeneous Charge Compression Ignition ( $\mathrm{HCCl}$ ) Engines," SAE Paper 892068.

8. Christensen, M., Johansson, B., Amneus, P. and Mauss, F., 1998, "Supercharged Homogeneous Charge Compression Ignition," SAE Paper 980787.

9. Christensen, M. and Johansson, B., 1998, "Influence of Mixture Quality on Homogeneous Charge Compression Ignition," SAE Paper No. 982454.

10. Christensen, M., Hultqvist, A. and Johansson, B., 1999, "Demonstrating Multi Fuel Capability of a Homogeneous Charge Compression Ignition Engine with Variable Compression Ratio," SAE Paper 199901-3679.

11. Christensen, M. and Johansson, B., 1999, "Homogeneous Charge Compression Ignition with Water Injection," SAE Paper 1999-01-0182.

12. Hultqvist, A., Christensen, M. and Johansson, B., 2000, "The Application of Ceramic and Catalytic Coatings to Reduce the Unburned HC Emissions from HCCI Engines," SAE Paper 2000-01-1833.

13. Olsonn, J.-O., Erlandsson, O. and Johansson, B., 2000, "Experiments and Simulation of a Six-Cylinder Homogeneous Charge Compression Ignition $(\mathrm{HCCl})$ Engine," SAE Paper 2000-01-2867.

14. Kimura, S., Aoki, O., Ogawa, H., Muranaka, S. and Enomoto, Y., 1999, "New Combustion Concept for Ultra-Clean and High-Efficiency Small DI Diesel Engines," SAE Paper 1999-01-3681.

15. Aceves, S.M., Flowers, D.L., Westbrook, C.K., Pitz, W.J., Smith, J.R., Dibble, R.W., Christensen, M., and Johansson, B., 2000, "A Multizone Model for Prediction of $\mathrm{HCCl}$ combustion and Emissions," SAE paper 2000-01-0327.

16. Aceves, S.M., Flowers, D.L., Martinez-Frias, J., Smith, J.R., Westbrook, C.K., Pitz, W.J., Dibble, R.W., Wright, J.F., Akinyemi, W.C., and Hessel, R.P., 2001, " A Sequential Fluid-Mechanic ChemicalKinetic Model of Propane $\mathrm{HCCl}$ Combustion," SAE Paper 2001-01-1027.

17. Smith, J.R., Aceves, S.M., Westbrook, C.K. and Pitz, W.J., 1997, "Modeling of Homogeneous Charge Compression Ignition ( $\mathrm{HCCl})$ of Methane," Proceedings of the 1997 ASME Internal Combustion Engine Fall Technical Conference, ICE-Vol. 29-3, Paper No. 97-ICE-68, pp. 85-90.

18. Martinez-Frias, J., Aceves, S.M., Flowers, D.L., Smith, J.R. and Dibble, R.W., 2000, "HCCl Engine Control By Thermal Management," SAE Paper 200001-2869.
19. Willand, J., Nieberding, R.-G., Vent, G. and Enderle, C., 1998, "The Knocking Syndrome - Its Cure and Potential," SAE paper 982483.

20. Kontarakis, G., Collings, N. and Ma, T., 2000, "Demonstration of $\mathrm{HCCl}$ Using a Single Cylinder Four-stroke SI Engine with Modified Valve Timing," SAE Paper 2000-01-2870.

21. Odaka, M., Suzuki, H., Noriyuki, K. and Hajime, I., 1999, "Search for Optimizing Control Method of Homogeneous Charge Diesel Combustion," SAE Paper 1999-01-0184.

22. Flowers, D.L., Aceves, S.M., Westbrook, C.K., Smith, J.R. and Dibble, R.W., 2001, " Detailed Chemical Kinetic Simulation of Natural Gas $\mathrm{HCCl}$ Combustion: Gas Composition Effects and Investigation of Control Strategies," ASME Journal of Engineering for Gas Turbines and Power, in press.

23. Heywood, J.B., 1988, Internal Combustion Engine Fundamentals, McGraw-Hill Inc., New York, NY.

24. Aceves, S.M., Smith, J.R., Westbrook, C.K. and Pitz, W.J., 1999, " Compression Ratio Effect on Methane $\mathrm{HCCl}$ Combustion," Journal of Engineering for Gas Turbines and Power, Vol 121, No. 3. 